\title{
First formal estimate of the world population of the Critically Endangered spoon-billed sandpiper Calidris pygmaea
}

\author{
Nigel A. Chark, Guy Q. A. Anderson, Jing Li, Evgeny E. Siroechiovikiy \\ Pavel S. Tomkovich, Christoph Zöckler, Rebecca Lee and Rhys E. Green
}

\begin{abstract}
The spoon-billed sandpiper Calidris pygmaea is a Critically Endangered shorebird that breeds in the Russian arctic and winters in coastal and estuarine habitats in Southeast Asia. We report the first formal estimate of its global population size, combining a mark-resighting estimate of the number of leg-flagged individuals alive in autumn 2014 with an estimate of the proportion of birds with flags from scan surveys conducted during the same period at a migration stop-over site on the Jiangsu coast of China. We estimate that the world breeding population of spoon-billed sandpipers in 2014 was 210-228 pairs and the post-breeding population of all age classes combined was $661-718$ individuals. This and related methods have considerable potential for surveillance of the population size of other globally threatened species, especially widely dispersed long-distance migrants.
\end{abstract}

Keywords Lincoln-Petersen population estimate, markresighting, migration, shorebird, spoon-billed sandpiper, Yellow Sea

To view supplementary material for this article, please visit https://doi.org/10.1017/Soo30605316000806.

Nigel A. Clark British Trust for Ornithology, The Nunnery, Thetford, Norfolk, $\mathrm{UK}$

GuY Q.A. ANDERSON RSPB Centre for Conservation Science, Royal Society for the Protection of Birds, Sandy, Bedfordshire, UK

JING LI Spoon-billed Sandpiper (Shanghai) Environment Protection Technology Co. Ltd., Yangpu District, Shanghai, People's Republic of China

Evgeny E. Syroechrovskiy All-Russian Institute for Ecology, Ministry of Natural Resources and Ecology of Russian Federation, Moscow, Russia, and BirdsRussia, Moscow, Russia

Pavel S. Toмкоvich Zoological Museum, Lomonosov Moscow State University, Moscow, Russia

ChRISTOPH ZöCKLeR Spoon-billed Sandpiper Task Force, c/o ArcCona Consulting, Cambridge, UK

Rebecca Lee Wildfowl \& Wetlands Trust, Slimbridge, Gloucestershire, UK

RHYS E. Green (Corresponding author) Department of Zoology, Conservation Science Group, University of Cambridge, David Attenborough Building, Pembroke Street, Cambridge, UK. E-mail reg29@cam.ac.uk

Received 27 March 2016. Revision requested 24 June 2016.

Accepted 20 July 2016. First published online 19 October 2016.

\section{Introduction}

The spoon-billed sandpiper Calidris pygmaea is one of 1 the most threatened migratory birds and is categorized as Critically Endangered on the IUCN Red List (BirdLife International, 2015). It breeds along a discontinuous narrow strip of $4,500 \mathrm{~km}$ of coastal tundra in the north-east arctic and subarctic zones of Russia in the Chukotka Autonomous Okrug and northern Kamchatka Kraj (Zöckler et al., 2010a). During the non-breeding season spoon-billed sandpipers migrate through the southern Russian Far East, Korea, China and Japan to winter in southern China, Thailand, Myanmar, Vietnam, Malaysia and Bangladesh (Clark et al., 2014; Zöckler et al., 2016). Coastal mudflats, including estuaries, are the main habitat in the non-breeding season.

The spoon-billed sandpiper's global population is thought never to have been particularly large. In the $1970 \mathrm{~s}$ the breeding population was estimated to be 2,00o-2,800 pairs (Flint \& Kondratiev, 1977). Similar assessments estimated the breeding population to be $<1$, 000 pairs in 2000, 560-900 pairs in 2002, 402-572 pairs in 2003 and 120-200 pairs in 2009 (Zöckler et al., 2010a). Declines were observed in recent decades at all breeding concentrations in arctic Russia where repeat counts have been made, with a mean annual rate of decline of $26 \%$ (range 19-50\%) at four monitored breeding sites in the decade up to 2009 (Zöckler et al., 2010a).

Research in the Gulf of Mottama (Myanmar), the site with the largest recent count of wintering spoon-billed sandpipers, indicated that the birds were killed frequently by hunters targeting larger shorebird species for food (Zöckler et al., 2010b). There are also reports of mortality caused by hunting and entanglement in fishing nets in other parts of the non-breeding range (Pain et al., 2011; Clark et al., 2014). There have been recent efforts to reduce this mortality (Clark et al., 2014).

Outside the breeding season, concentrations of spoonbilled sandpipers are known from a relatively small number of sites around the Yellow Sea (China and South Korea) in autumn and spring. In autumn, birds move to wintering grounds in a number of South-east Asian countries between Bangladesh and south China (Zöckler et al., 2016). Conversion of intertidal areas for human use is believed to be having significant effects on migratory shorebirds along 


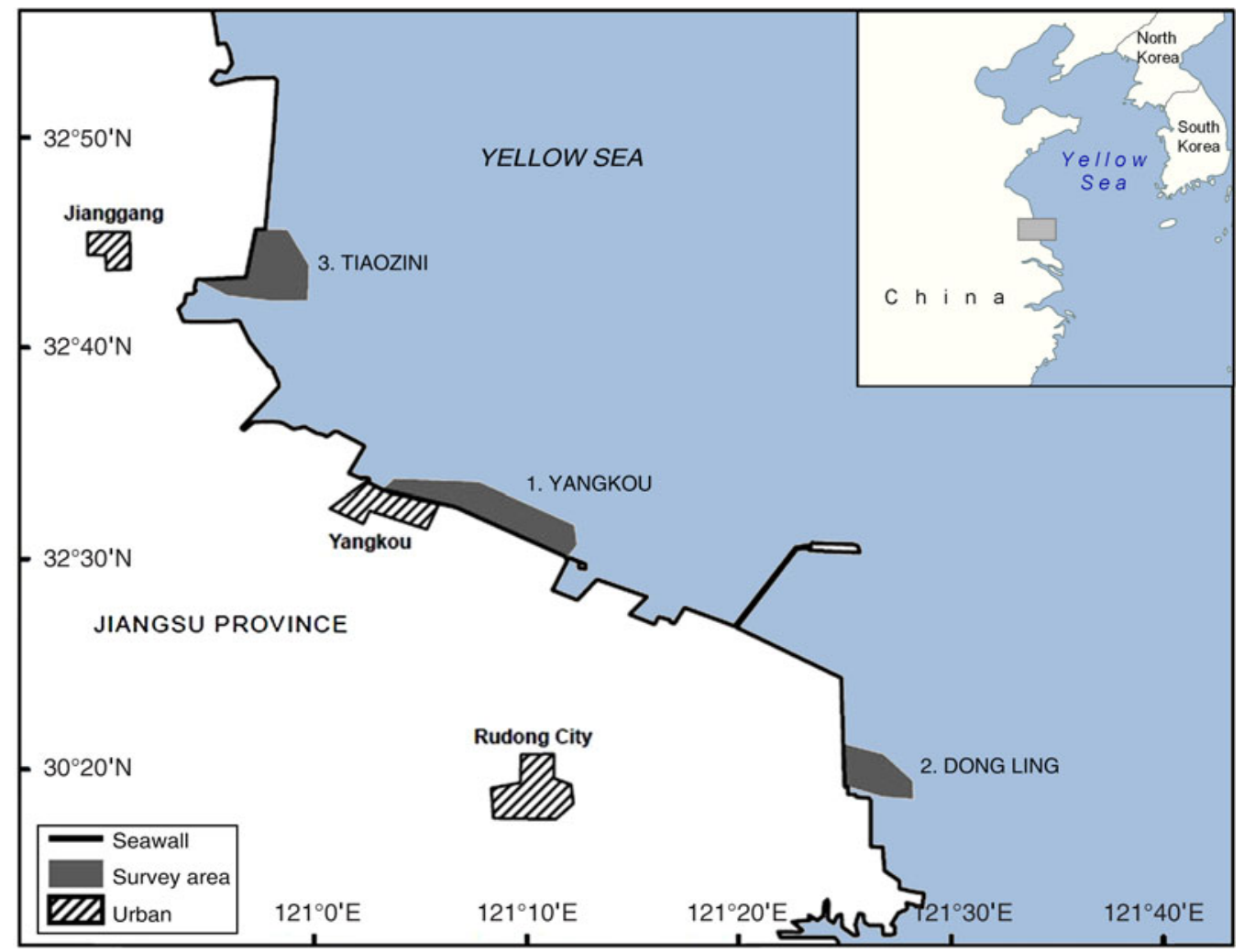

FIG. 1 Locations along the Jiangsu coast of northern China where scan surveys were conducted in September 2014 to estimate the world population of the spoon-billed sandpiper Calidris pygmaea. The horizontal extent of the area shown on the main map is $190 \mathrm{~km}$.

the East Asian-Australasian flyway, where more shorebird species are declining than in any other flyway in the world (Kirby, 2010). The spoon-billed sandpiper is believed to be among the species most threatened by these changes.

Accurate estimates of population size are important in making informed decisions about the protection and management of threatened species and their habitats. Here we describe the first formal estimate of the world population size of the spoon-billed sandpiper.

\section{Study area}

Data on the proportion of individual spoon-billed sandpipers marked with flags were obtained from systematic scan survey observations made on the coast of southern Jiangsu Province, People's Republic of China (Fig. 1). Located in the south-west corner of the Yellow Sea, this $120 \mathrm{~km}$ coastline of extensive mud and sand flats had the largest concentrations of spoon-billed sandpipers counted anywhere in recent years and represents the most important known autumn migration staging and moulting area (Tong et al., 2012; Bai et al., 2015). A minimum of 143 individuals were recorded there in October 2013 (Tong et al., 2014). The majority of recent records have come from three areas along the Jiangsu coast: (1) the coast adjacent to the port of
Yangkou (Rudong County, Nantong Prefecture), (2) Dong Ling (Rudong County, Nantong Prefecture; $50 \mathrm{~km}$ southwest of Yangkou), and (3) Tiaozini (Dong Tai County, Yangcheng Prefecture; $30 \mathrm{~km}$ north-west of Yangkou). These three areas all have large expanses of open mudflat at relatively high elevations, which are last to be flooded on a rising tide and first to be uncovered on a falling tide. During migration periods large concentrations of shorebirds are regularly observed at high-tide roosts adjacent to these areas, on reclaimed land behind the seawall.

\section{Methods}

\section{Principle of the population estimation method}

We used an adapted version of the Lincoln-Petersen method (Le Cren, 1965) to estimate the world population of spoon-billed sandpipers. At its simplest this method requires (1) an estimate of the absolute number of individuals in the population carrying marks within a given time period, and (2) an unbiased estimate of the proportion of the entire population that is marked during the same period. The size of the population is then estimated by dividing estimate (1) by estimate (2). We used mark-resighting analysis of spoonbilled sandpipers marked individually with engraved plastic 
leg flags (Clark et al., 2005) and later recorded in many parts of the global range to make an estimate (1) of the number of marked individuals alive in September-October 2014. To obtain estimate (2) a team of five experienced observers systematically scanned spoon-billed sandpipers at an autumn migration stop-over site on the Jiangsu coast of China in late September 2014 in a survey specifically designed to estimate the proportion of birds with flags. We considered using an alternative to the Lincoln-Petersen estimator, the joint hypergeometric estimator, as implemented through NOREMARK (White, 1996), which has been used effectively to estimate other shorebird populations (Gunnarsson et al., 2005). However, the situation for spoonbilled sandpipers has a number of special attributes, described in the next section, which led us to use a modified Lincoln-Petersen estimator.

\section{Complications that required an adapted method}

An important complication in our situation is that young of the year were present on the Jiangsu coast during the scan surveys but were not part of the population we wanted to estimate, as young birds in their first year are likely to differ from older birds in their migratory routes and schedules. Had it been possible to age every bird that was scanned for flags we could simply have discarded the sightings of young of the year. However, because reliable ageing was only possible for the subset of birds seen well enough to do so, it was necessary to allow for age composition by estimating separately the proportion of scanned birds that were older than young of the year and the proportion of all birds that were flagged, and then using the two estimates to calculate the proportion of only the older birds that were flagged, as described below.

A second complication was that the scan survey data included multiple sightings of the same individuals, but it was not possible to know how many times each bird was scanned, at least for the unmarked individuals. Although the number of individual marked sandpipers observed during scan surveys was known approximately from their tag inscriptions, there was no practical way to determine reliably the absolute number of unmarked birds. Hence, the proportion of marked birds could not be determined reliably from the number of marked individuals relative to the total number of all individuals, but only from the proportion of scan events at which a mark was detected. Because of this the individual scan records (flagged or not flagged) are not statistically independent of one another. The problem is analogous to a thought experiment in which one wishes to estimate the proportion of black balls inside a cloth bag containing an unknown mixture of white and black balls. The estimation can be done based upon a sample of balls withdrawn from the bag. However, the balls can either be (1) kept out of the bag after removal, or (2) replaced inside the bag after sampling so that, in theory, the same ball can be sampled multiple times. Our scan surveys are like case (2), which makes the assumptions about the statistical independence of individual records underlying the joint hypergeometric estimator method, and confidence intervals based upon it, invalid. Although there is no reason to expect that repeated scanning of some of the same marked and unmarked individuals would lead to a biased estimate of the proportion of birds with flags, the confidence limits of the proportion would be too narrow if it were erroneously assumed that individual scan events were statistically independent. This problem was addressed by dividing the scan data into groups of consecutive scans made at one site by the same observer and using a bootstrap procedure to obtain confidence limits of the estimated proportion, as described below. The principal assumptions of our adapted method are listed and assessed in detail in Supplementary Table S1.

\section{Leg flagging and flag reading throughout the known range}

Breeding adult spoon-billed sandpipers were captured for marking in 2013 and 2014 by using traps placed on nests at the site with the largest known breeding population, at Meinypil'gyno (Chukotka, Russia). Each captured bird was marked with a numbered metal ring on the right tibiotarsus and a plastic leg flag engraved with two alphanumeric characters on the left tibiotarsus. The leg flag was sealed with glue or heat welded. Further details of the study site and fieldwork are in Zöckler et al. (2010a). Young birds were marked as chicks in the same way, except that flags with one alphanumeric character were used on a few birds and the flags were placed on the right leg. Some of the birds marked as chicks were derived from a head-starting programme (Clark et al., 2014) in which eggs were removed from nests at Meinypil'gyno and incubated and reared artificially. The resulting juveniles were released at Meinypil'gyno at the time that wild juveniles were fledging.

Using telescopes, binoculars or photography, leg flags were read at Meinypil'gyno, with virtually all breeding adults that were detected at the site being checked for rings. Leg flags were also read by fieldworkers and birdwatchers in the non-breeding range, mostly on the Jiangsu coast (China) and in the wintering areas between South China and Bangladesh. Resightings were categorized as being from the breeding grounds in June and July and from non-breeding areas during August-May. All resightings up to the end of January 2016 were used.

\section{Systematic scan survey on the Jiangsu coast}

Using binoculars and telescopes (Swarovski ATS/STS 80 and Leica APO-Televid 82), five observers (NAC, GQAA, 
Richard Hearn, James Phillips and Andrew Schofield) searched for spoon-billed sandpipers within flocks of small shorebirds in the three areas described above, over a 9-day period (21-29 September 2014). Fieldwork was primarily conducted just before, during and just after high tide, when shorebirds were concentrated; at mid and low tides they dispersed widely across the extensive mudflats. The fieldwork period coincided with a series of spring tides, which were high enough to concentrate shorebirds on the upper shore. All five observers operated at the same site during a single tidal cycle but recorded data independently, typically several hundred metres apart, to avoid scanning the same flocks. Each flock encountered was scanned thoroughly from one side to the other, until a spoon-billed sandpiper was located. Whether or not the bird was flagged, details of any marks and, where possible, plumage characteristics were recorded rapidly before continuing the scan to find the next spoon-billed sandpiper. Care was taken to view as many spoon-billed sandpipers as possible for long enough to determine whether they were leg-flagged or not. However, the tibiotarsi of some birds were concealed by feathering, or the birds were too distant or flew away before they could be checked, so $15 \%$ of spoon-billed sandpipers seen on scan surveys were excluded from analysis. The scanning procedure was repeated until the entire flock of shorebirds had been scanned or the birds flew away. The observer then moved to locate and scan the next shorebird flock.

For individuals that could be seen clearly enough, notes taken on their plumage characteristics were used to determine their age class. We use the abbreviations from the North American Bird Banding Manual (Gustafson et al., 1997) to denote age classes: hatching year (HY), which comprises birds capable of sustained flight and known to have hatched during the focal calendar year; after hatching year (AHY), which comprises birds known to have hatched earlier than the focal calendar year; second year (SY), which comprises birds known to have hatched in the calendar year preceding the focal calendar year; and after second year (ASY), which comprises birds known to have hatched earlier than the calendar year preceding the focal calendar year. The class AHY comprises SY and ASY. Substantial variation in the progression of post-juvenile moult was noted in HY spoon-billed sandpipers in late September 2014. Some individuals were largely still in juvenile plumage, and therefore easy to age. Others had completed their postjuvenile moult, retaining only juvenile lesser and median wing coverts, and tertials. The retained juvenile coverts showed strong contrast between dark feather centres and pale fringes, giving a scalloped appearance, unlike replaced feathers on older birds, which showed less contrast. The AHY spoonbills present probably included both SY (hatched in 2013) and ASY individuals (hatched in 2012 or earlier) but these two classes cannot be distinguished reliably using plumage characteristics. Many ASY birds retained some of the rufous feathers of their breeding plumage and were therefore easy to age accurately. Others of this age class had progressed further through their post-breeding moult and were in full grey and white non-breeding plumage. Reliable separation of $\mathrm{HY}$ and AHY birds required close views, good light and experienced observers. For this reason, age determination was not possible for all spoon-billed sandpipers recorded on the scan surveys.

\section{Ratio of observations of leg-flagged AHY spoon-billed sandpipers to the total number of birds of any age checked for flags}

We obtained an estimate $A$ of the proportion of leg scans of spoon-billed sandpipers of any age, including those of indeterminate age, in which an engraved leg flag was seen to be carried by a bird older than first calendar year. Only some of these scans were of birds for which the age class (HY or AHY) could be determined from plumage characters. However, the age of all the flagged birds was determined from the inscription or the position of the tag. The same flock was sometimes scanned immediately after a previous scan to check the results. However, repeats were consistent, so only the first scan was used in the calculations. Scans known or thought to include some but not all of the same individuals seen on a previous scan were included when, for example, a flock of shorebirds flew in to merge with another flock that had already been scanned. Flocks scanned at the same site on a different tidal cycle would also have included some of the same birds scanned on other surveys.

The estimate of $A$ was obtained by dividing the number of records of AHY spoon-billed sandpipers with engraved leg flags by the total number of scan events. Confidence limits for $A$ were determined by the following bootstrap method. The scans recorded by each of the observers were placed in chronological order. Groups of consecutive scans made by one observer at a site were pooled to give sampling units comprising at least 20 individuals scanned (range 20-53). There were 26 such units (3-10 per observer). We took a bootstrap set of 26 units drawn at random with replacement from the observed set of 26 units and calculated $A$ from this set. We repeated this procedure 10,000 times and took the central 9,500 of these bootstrap values of $A$ to define its $95 \%$ confidence limits.

Ratio of observations of AHY spoon-billed sandpipers to the total number of checks of birds whose age could be determined from plumage characters

As described above we were able to identify individuals as being HY or AHY from plumage characters on some of the scan surveys. We obtained an estimate $B$ of the proportion 
of such sightings where the bird was recorded as being AHY. Confidence limits for $B$ were determined by a bootstrap method similar to that described above for $A$. In this case, consecutive scans were grouped to give sampling units comprising at least 10 individuals scanned and aged (range 10-21), rather than 20, giving a total of 34 such units (10 and 24 for the two observers). The use of bootstrap units comprising fewer sightings per unit was considered appropriate because the proportion $B$ being estimated was not as close to one as the proportion $A$ was to zero. We took a bootstrap set of 34 units drawn at random with replacement from the observed set of 34 units and calculated $B$ from this set. We repeated this procedure 10,000 times and took the central 9,500 of these bootstrap values of $B$ to define its $95 \%$ confidence limits.

Number of leg-flagged AHY spoon-billed sandpipers estimated to be alive in September-October 2014

We listed all individuals with engraved leg flags that were AHY in 2014 and whose identity was established by flagreads at any location in September 2014 or at any time later, up to the end of January 2016. There were 21 such individuals. Hence, the minimum number of AHY spoonbilled sandpipers with engraved leg flags known to be alive in September-October 2014 was 21. One of these birds had been reared and released as part of the headstarting programme, leg-flagged as a chick in the summer of 2012, and was 2 years old in 2014. Three were headstarted, flagged and released as juveniles in 2013 and were 1 year old in 2014. Six birds had been captured and flagged as breeding adults in 2013, and 11 in 2014.

We used the Jolly-Seber method and the notation of Seber (1973) to estimate the number $M$ of AHY spoon-billed sandpipers with engraved leg flags alive anywhere in the world in September-October 2014. We counted the number $m$ of these flagged birds seen anywhere in the world in September-October 2014 and the number $r$ of the set of birds seen in that period that were also seen anywhere in the world at some time after October 2014. We also counted the number of flagged AHY individuals $z$ known to be alive in September-October 2014 because of previous and subsequent sightings but whose flag codes were not recorded during that period. Using the version of the Jolly-Seber method that adjusts for small sample bias (Jolly, 1965), we estimated the number of flagged AHY individuals alive anywhere in the world in September-October 2014 using the equation $M=m+(m+1) z /(r+1)$.

Confidence limits for $M$ were determined by a bootstrap method. We drew a set of 21 resighting histories at random, with replacement, from the 21 observed resighting histories and calculated $M$, as described above. We repeated this procedure 10,000 times and took the central 9,500 of these bootstrap values of $M$ to define its $95 \%$ confidence limits.
World population size of AHY spoon-billed sandpipers

We used the results of the calculations described above in combination to estimate the world population of AHY spoon-billed sandpipers. We first estimated the proportion of AHY individuals on the Jiangsu coast that were carrying engraved leg flags as $A / B$. The world population was then calculated by dividing the estimated number of flagged AHY spoon-billed sandpipers alive at the time of the scan surveys $M$ by this proportion: $M^{\star} B / A$. We aligned the bootstrap values of $A, B$ and $M$ in random order, used these to generate 10,000 values for the world population size of AHY individuals and took the central 9,500 of these to define its $95 \%$ confidence limits.

Interpolation and extrapolation of the breeding population and total world population size

Our procedure estimates the numbers of only a subset of the age classes in the spoon-billed sandpiper population: the AHY birds, comprising the SY and ASY classes. The breeding population of spoon-billed sandpipers is smaller than the AHY population because few SY birds breed. The total post-breeding population is larger than the estimated AHY population because it includes HY birds. We obtained approximate estimates of the world breeding population and total population by combining the estimated number of AHY birds with information on the proportions of birds in various age classes from a Leslie matrix model of the population immediately after the breeding season (Caswell, 2001). In the model we assumed that there were three age classes: HY, SY and ASY. We took the annual survival of all ASY birds of both sexes to be that determined for breeding adults from mark-recapture studies at Meinypil'gyno during 2003-2009 (o.76 \pm SE 0.077; Zöckler et al., 2010a). We assumed that the mean number of fledglings per pair of ASY birds per year was the mean number of fledglings per breeding pair observed at Meinypil'gyno during 2003-2009 (0.61 \pm SE 0.14; Zöckler et al., 2010a). We assumed that the sex ratio at fledging was 1:1, that all birds attempted to breed for the first time at 2 years of age and that breeding occurred in every year thereafter. We assumed that annual survival was equal in the 2 years before breeding age (i.e. it was the same for HY and SY birds) and the same for both sexes. Surveys at Meinypil'gyno indicated that the breeding population there was approximately stable during 2010-2015, so we set the survival rate from fledging to 2 years old to give a stable breeding population size. Using this model we estimated the ratio of the number of ASY birds at the end of the breeding season to the number of AHY birds, and the ratio of the number of all individuals at the end of the breeding season (HY, SY and ASY) to the number of AHY birds when the age structure of the simulated population was stable. We multiplied the estimated number of AHY birds derived from the mark-resighting and scan 
surveys, as described above, by these ratios to obtain estimates of breeding and total world population sizes.

We allowed for uncertainty in our estimates of the Leslie matrix model ratios using a Monte-Carlo method (Manly, 2006). We used the means and standard errors of adult survival and breeding productivity given by Zöckler et al. (2010a) and randomly generated normal deviates to generate a set of 10,000 Monte-Carlo values of these two variables. We checked the random values generated for any that were outside the allowable range (i.e. survival values $<0$ or $>1$ and breeding productivity $<0$ ). Seven of the 10,000 survival values were $>1$, and we set these to 1 . No survival or productivity values were $<0$. We then used the procedure described above to generate 10,000 pairs of values of the Leslie matrix model ratios. We used the Monte-Carlo values of these ratios in random order and aligned them with the randomly ordered bootstrap values of population size described above to obtain confidence limits for the extrapolated and interpolated sizes of population components.

\section{Results}

Ratio of observations of leg-flagged AHY spoon-billed sandpipers to the total number of checks of birds of any age for flags

A total of 745 leg-checks were made to determine whether birds of any age were carrying engraved flags. Birds with engraved flags were seen on 36 of these checks, of which 29 records were of flagged AHY birds, from at least seven individuals, and seven records were of flagged HY birds, from at least three individuals. No flagged SY birds were identified on scan surveys. Hence, the ratio of observations of leg-flagged AHY birds to the total number of checks of birds of any age was $A=29 / 745=0.039$.

Ratio of observations of AHY spoon-billed sandpipers to the total number of checks of birds whose age could be determined

A total of 441 age-checks based upon plumage characters were recorded. Birds classed as AHY were seen on 410 of these. Hence, $B=410 / 441=0.9297$. Combining this value with the estimate of $A$ described above gives an estimate of the proportion of AHY birds that were carrying engraved leg flags, $A / B=0.042$.

\section{Number of leg-flagged AHY spoon-billed sandpipers estimated to be alive in September-October 2014}

The number of AHY birds with engraved flags seen anywhere in the world in September-October 2014 was 13, of which one was SY and the rest were ASY $(m=13)$. These birds were observed on the Jiangsu coast, except for a flagged ASY bird recorded in South Korea. Of the individuals included in $m$, 11 were also seen after SeptemberOctober $2014 \quad(r=11)$. Eight flagged AHY birds were known to be alive in September-October 2014 because of previous and subsequent sightings but were not seen during that period $(z=8)$. Most of the 19 individuals seen after October 2014 were resighted on several occasions, and 16 were seen in more than one country. Seventeen of these birds were seen in Russia, two in South Korea, 14 in China, two in Bangladesh and two in Thailand. We estimated the number of flagged AHY birds $M$ alive anywhere in the world in September-October 2014 to be $m+(m+1) z /$ $(r+1)=13+(14 \times 8 / 12)=22.3$.

We also performed the same calculation using only the 18 resighting histories for ASY birds, after excluding birds that were SY in 2014. The values of $m, r$ and $z$ were 12,10 and 6 , respectively. Hence, the estimated number of flagged ASY individuals alive anywhere in the world in September-October $2014 M$ was $m+(m+1) z /(r+1)=12+(13 \times 6 / 11)=19.1$.

Most SY spoon-billed sandpipers do not breed (Tomkovich, 1994) and they may not travel to the breeding grounds. This could lead to a smaller proportion of SY than ASY birds being on the Jiangsu coast and at other stop-over sites further north in autumn. We noted that 10 of the 16 flagged ASY birds known to be alive during SeptemberOctober 2014 from previous and subsequent records were recorded during that period on the Jiangsu coast or in South Korea (63\%), but only one of three $(33 \%)$ of the equivalent set of SY birds was seen in these localities (on the Jiangsu coast). No conclusion can be drawn with such small samples (Fisher's exact test, one-tailed $\mathrm{P}=0.386$ ) but the possibility that a smaller proportion of SY than ASY birds visit the Jiangsu coast in autumn, or that they spend less time there, should be considered.

\section{World population size}

We combined the Jolly-Seber estimate of the number of flagged AHY birds alive in September-October 2014 with the estimated proportion of AHY birds carrying flags from the Jiangsu coast scan surveys, as described in the Methods section, to estimate the world population of AHY birds. The results, together with bootstrap 95\% confidence limits, are in Table 1. If we assume that equal proportions of SY and ASY birds visit the Jiangsu coast, then the estimated world population of AHY birds is 533 individuals. After multiplying by the Leslie matrix model ratios (see Methods), this is equivalent to 420 ASY birds (210 pairs) and a total post-breeding population, including HY, SY and ASY birds, of 661 individuals.

We noted that it is possible that a smaller proportion of SY than ASY birds may visit the Jiangsu coast in autumn. 
TABLE 1 Parameter estimates used to estimate the world population of spoon-billed sandpipers Calidris pygmaea, with bootstrap 95\% confidence limits. Results are shown for the proportion of birds in the age class after hatching year (AHY) on the Jiangsu coast carrying engraved leg flags, based on scan surveys and estimates of world populations based upon these proportions and mark-resighting estimates of the numbers of leg-flagged individuals alive anywhere in the world at the time of the scan surveys. Population estimates are made separately assuming either that equal proportions of second year (SY) and after second year (ASY) birds alive were on the Jiangsu coast in September 2014 or that no SY birds were on the Jiangsu coast.

Parameter

Estimate $(95 \% \mathrm{CI})$

Proportions of flagged birds in scans

Scans of flagged AHY birds as a proportion of scans of birds of all ages $(A)$

Scans of AHY birds as a proportion of all scans with age determination $(B)$

$0.039(0.027-0.051)$

Proportion of AHY birds with flags $(A / B)$

$0.930(0.904-0.952)$

$0.042(0.029-0.055)$

\section{Population estimates assuming both ASY and SY birds were on the Jiangsu coast}

No. of flagged AHY birds alive anywhere $(M)$

$22.3(21.0-26.0)$

$533(398-792)$

$420(308-631)$

$210(154-315)$

$661(494-999)$

World population of ASY pairs based upon Leslie matrix model

Population estimates assuming only ASY birds were on the Jiangsu coast

No. of flagged ASY birds alive anywhere $(M)$

$456(342-683)$

World population of ASY birds $(M B / A)$

$228(171-342)$

World population of ASY pairs

$718(522-1,113)$

We assessed the possible effect of this by repeating our calculation of world population size on the assumption that no SY birds visit the Jiangsu coast. Although we know that this is unrealistic, because one flagged SY bird was seen on the Jiangsu coast, it is a test of the sensitivity of our results to a possible difference in behaviour between SY and ASY birds. To do this we used the number of flagged ASY birds estimated to be alive in September-October 2014 in place of the equivalent estimate for AHY birds. In this case our method estimates the world population of ASY birds only. We divided the Jolly-Seber estimate of the number of flagged ASY birds alive in September-October 2014 by the estimate from the Jiangsu coast scan surveys of the proportion of AHY birds that were carrying flags. This yielded a world population estimate of 456 ASY birds (228 pairs) and a total post-breeding population size of all age classes of 718 individuals (Table 1).

\section{Discussion}

Effect of the failure of a key assumption on the population estimate

We assessed the likely impact on the accuracy of the world population estimate of most of the principal assumptions of our method (Supplementary Table S1). With the exception of Assumption 2 (Supplementary Table $S_{1}$ ), probable effects were considered to be small. However, Assumption 2 has the potential to bias the estimate substantially in either direction. We assumed that the probability that a leg-flagged AHY spoon-billed sandpiper would visit the Jiangsu coast in autumn and be recorded there on the scan surveys was the same as for an AHY bird with no flag. We think that the design of our scan survey method was sufficiently robust that we obtained an unbiased estimate of the proportion of AHY birds present on the Jiangsu coast that were carrying engraved flags. Hence, the critical untested assumption is that the proportions of marked and unmarked AHY spoonbilled sandpipers visiting the Jiangsu coast in autumn are the same. We assessed the consequences of failure of this assumption using a model described in Supplementary Material 1. We show that our method will overestimate population size if the proportion of flagged birds moving to the Jiangsu coast in autumn is less than the equivalent proportion for unmarked birds, and vice versa. The most plausible reason why the probability of visiting the Jiangsu coast might differ between flagged and unflagged birds is that birds from different parts of the breeding range are more or less likely to migrate through the Jiangsu coast in autumn. Given that nearly all of the leg flagging has been of birds breeding at one site, Meinypil'gyno, the probability of flagged birds migrating through the Jiangsu coast would differ from that for birds with no flag if the probability was different for birds breeding in different regions. In Supplementary Material 1 we show that, even with extreme failure of this critical assumption, our method is unlikely to overestimate the world population of spoon-billed sandpipers by more than a factor of two or three because of differential migration of birds with and without flags. Hence, even 
with extreme assumptions about this potential source of bias, the world breeding population is likely to be at least 70-110 pairs. However, there is no equivalent constraint on the degree to which our estimate might be too low because of differential migration of flagged and unflagged birds.

Tags applied to wild birds sometimes affect their behaviour and demographic rates directly. The critical issue for the accuracy of our population estimate is whether legflagging itself influenced the migration route used. A review of the effects of geolocators mounted on leg flags or rings on hatching success, return rates and breeding movements of migratory shorebirds (Weiser et al., 2016) found some effects on demographic rates but none on breeding movements. Negative effects of geolocators on return rates increased with the mass of the tag relative to body mass, with no apparent effect of the lightest tags. Even the smallest geolocators (c. $0.4 \mathrm{~g}$ ) are larger and heavier than the $0.1 \mathrm{~g}$ flags we applied to spoon-billed sandpipers, so we think that effects of flagging on survival, and especially on migration routes, are unlikely.

\section{Implications of our estimates for the spoon-billed} sandpiper's Red List status

The spoon-billed sandpiper is categorized as Critically Endangered on the IUCN Red List, based upon criteria A2abcd, $\mathrm{A}_{3} \mathrm{bcd}, \mathrm{A}_{4} \mathrm{abcd}$ and $\mathrm{C} 2 \mathrm{a}(\mathrm{i})$ (BirdLife International, 2015). The criteria with an A prefix involve observed, estimated, inferred, suspected or (for $\mathrm{A}_{3}$ and $\mathrm{A}_{4}$ ) projected changes in population size over 10 years or three generations in the past $\left(\mathrm{A}_{2}\right)$, future $\left(\mathrm{A}_{3}\right)$ or encompassing both past and future (A4) (IUCN, 2001). Our estimate of the world population of the spoon-billed sandpiper is the first to be made using a formal statistical approach, so it provides no information on recent population changes. Hence, the application of the A criteria to determine the species' Red List category is unaffected by our results. Assignment of a species to the Critically Endangered category based on criteria with a $\mathrm{C}$ prefix requires that the population has fewer than 250 mature individuals, with C2a(i) being satisfied if there is also an observed, projected or inferred continuing decline in numbers of mature individuals, and no subpopulation estimated to contain $>50$ mature individuals (IUCN, 2001). Given that the lower bound of the $95 \%$ confidence interval of our estimate of the number of mature individuals (i.e. those in their third calendar year or older) was $>250$ ( 308 or 342 individuals, depending upon assumptions), it seems unlikely that the species qualifies as Critically Endangered based on the C criteria, although it would qualify as Endangered. We emphasize that this does not affect the species' Red List categorization at present because it is correctly assigned based upon the A criteria, based upon recent observed declines. However, if the rapid population decline of the recent past ceases for a period of 10 years or three generations but the population size remains below 2,500 mature individuals, future assessments may recategorize the species as Endangered (IUCN, 2001). In any case, we stress that our method requires repetition and validation before it is used for Red List assessments.

\section{Proportion of the estimated world population of spoon-billed sandpipers recorded breeding and wintering at known sites}

The expert assessment by Zöckler et al. (2010a) was that the total breeding population of spoon-billed sandpipers in 2009 was $120-220$ pairs. The upper limit of this range is similar to the 208 breeding pairs we estimate based upon the assumption that both SY and ASY birds are present at the Jiangsu coast in autumn, and the 228 pairs estimated if only ASY birds are assumed to be present. However, the total given by Zöckler et al. (2010a) included estimates for some former breeding sites where recent counts were not available. Since 2009 a total of 25-34 breeding pairs have been located. Hence, the location of only $11-16 \%$ of the breeding population of spoon-billed sandpipers is known in a typical year.

When Zöckler et al. (2010a) made their population estimate in 2009, numbers of pairs at the three sites where regular monitoring had taken place were declining by $26 \%$ per annum. Evidence from Meinypil'gyno, the one site where there has been detailed recent annual monitoring, suggests that the population has been essentially stable since 2010. If it had been continuing to decline at $26 \%$ per annum the total breeding population would be expected to have been 15-26 pairs in 2014. Our results indicate that the species' breeding population is substantially larger than that. Since 2009 there has been considerable focus on conservation measures to increase the survival of spoon-billed sandpipers in their stopover and wintering areas through reducing hunting, bycatch in fishing nets and habitat loss. The evidence from this population estimate and the stability of the breeding population at Meinypil'gyno suggests that at least some of these efforts may be having a positive effect.

A summary of recent information on the winter distribution and abundance of spoon-billed sandpipers reported results for South China (minimum 19, maximum 33), Vietnam (8-13), Thailand (11-17), Myanmar (188-260) and Bangladesh (16-56), giving a winter total of 242-379 individuals (Zöckler et al., 2016). This represents $37-57 \%$ of our estimate of the world population of spoon-billed sandpipers of all ages, based upon the assumption that both SY and ASY birds were present at the Jiangsu coast in autumn, and 34$53 \%$ if only ASY birds were assumed to be present. Even if we take the maximum total known winter population (379) and the lower $95 \%$ confidence limit of the lower of the two world population estimates (494), it appears that the location of c. $25 \%$ of the world's spoon-billed sandpipers in winter is unknown. It is uncertain whether the missing birds are using sites that have not yet been surveyed or if the numbers actually wintering at some surveyed sites are larger than the 
numbers counted. Counting spoon-billed sandpipers amongst flocks of many thousands of small shorebirds is difficult, especially when all species are in their grey winter plumage. In addition, many of the known wintering sites are large and difficult to access, so it is difficult to be confident that all the spoon-billed sandpipers present have been detected.

Conservation action to protect the habitat of spoonbilled sandpipers in the breeding and non-breeding seasons and to reduce the impact of deliberate hunting and of bycatch in fishing nets is likely to be hampered by this incomplete knowledge of their distribution.

\section{Sites of international importance for the spoon-billed sandpiper}

Annual survival rates of three other species of arcticbreeding scolopacid shorebirds with declining populations, which, like the spoon-billed sandpiper, utilize the intertidal zones of China's Yellow Sea coast during migration, have declined markedly in recent years, during a period of substantial losses of shallow sea areas to claim land for human use (Piersma et al., 2015). The seasonal pattern of change in survival of these species suggests that elevated mortality during the migration seasons, caused by habitat loss in migration stop-over sites in the Yellow Sea, is a plausible explanation for their population declines. These findings highlight the potential importance of more effective protection of migration stop-over sites of the spoon-billed sandpiper in China and throughout the species' range.

Under criterion 6 of the criteria for assessing the international importance of wetlands agreed by the Contracting Parties to the Ramsar Convention on Wetlands of International Importance, a wetland is considered to be internationally important if it regularly holds at least $1 \%$ of the population of a waterbird species (Ramsar Convention Bureau, 1988). Our results suggest that the qualifying number of spoonbilled sandpipers for designation of a site as being internationally important for the species should therefore be seven. Using this criterion several candidate sites of international importance can be identified, including Meinypil'gyno (Russia), sites on the Jiangsu coast (China), including Tiaozini, which is currently under threat from the reclamation of intertidal areas, sites on the Guangdong coast (China), the Mekong Delta (Vietnam), the inner Gulf of Thailand, Nan Thar and the Gulf of Mottama in Myanmar, and Sonadia, Sandwip Island and Nijhum Dweep in Bangladesh (Zöckler et al., 2010a, 2016; Bai et al., 2015).

Proposals for future studies to determine the population size of the spoon-billed sandpiper

Our finding that the locations of substantial proportions of the breeding and wintering populations of spoon-billed sandpipers are unknown highlights the value of continuing to search additional areas for the species and conducting thorough and systematic surveys at known sites. As well as providing valuable information on migration routes and timing, leg flagging of spoon-billed sandpipers at more breeding, passage and wintering sites would help to make our method of population estimation more robust against the possible failure of its key assumption that marked and unmarked birds have the same probability of being present at a given scan survey site. The method could also be checked by comparing scan surveys conducted at various non-breeding sites and by repeating the surveys on the Jiangsu coast in autumn in other years and also in spring, when the species is also present on its northwards migration. If the method is found to be robust, continued leg flagging and regular repetition of the scan surveys would facilitate assessment of the trend in population size. If leg flagging and scan surveys were to be conducted at more sites widely distributed in the known non-breeding range, it would be possible to use more sophisticated analytical methods. In particular, the use of multistate mark-resighting models (Bailey et al., 2010) would, with sufficient sample sizes, facilitate estimation of the variation in probabilities of movement between various parts of the range. The potential bias caused by this variation could then be allowed for.

Wider implications for population surveillance of globally threatened species

Our method and related methods, which are based upon combining estimates of the proportion of birds carrying marks from a scan survey with mark-resighting estimates of numbers of individually marked birds alive at the time of the survey, could be applied to other bird species, including globally threatened species. This approach is especially suitable for widely-dispersed migratory species for which incomplete information on geographical distribution makes complete censuses from coordinated counts across the range impractical. Our analysis suggests that the method can provide repeatable population estimates with a useful level of precision, even for small populations in which only a few individuals are marked.

\section{Acknowledgements}

We thank Egor Loktionov and Roland Digby for their invaluable help during bird flagging. The hard work and skill demonstrated by Richard Hearn, James Phillips and Andrew Schofield in their contributions to the scan surveys is appreciated. We thank Zhang Lin and Zhang Jun for help on the Jiangsu coast, and the many observers who contributed records of leg-flagged sandpipers from many parts of their global range. Sayam U. Chowdhury kindly helped to 
assemble the global database of flag resightings. Nicola Crockford, Paul Donald and Stuart Butchart provided helpful advice. We are grateful to Leica Camera AG for providing optical equipment.

\section{Author contributions}

NAC and GQAA designed and led the scan surveys. JL facilitated and participated in fieldwork on the Jiangsu coast. EES and PST coordinated and conducted leg flagging in Russia. CZ coordinated and conducted leg flag reading and other surveys of spoon-billed sandpipers throughout their global range. RL compiled the leg flag resighting data. REG, NAC and GQAA designed and conducted the analyses and drafted the manuscript. All authors commented on the manuscript.

\section{References}

Bai, Q., Chen, J., Chen, Z., Dong, G., Dong, J., Dong, W. et al. (2015) Identification of coastal wetlands of international importance for waterbirds: a review of China Coastal Waterbird Surveys 20052013. Avian Research, 6, 12.

Bailey, L.L., Converse, S.J. \& Kendall, W.L. (2010) Bias, precision, and parameter redundancy in complex multistate models with unobservable states. Ecology, 91, 1598-1604.

BirdLife International (2015) Calidris pygmaea. The IUCN Red List of Threatened Species 2015: e.T22693452A77507581. Http://dx. doi.org/10.2305/IUCN.UK.2015-4.RLTS.T22693452A77507581.en [accessed 1 February 2016].

Caswell, H. (2001) Matrix Population Models. 2nd edition. Sinauer Associates, Inc., Sunderland, USA.

Clark, N., Gillings, S., Baker, A.J., González, P.M. \& Porter, R. (2005) The production and use of permanently inscribed leg flags for waders. Wader Study Group Bulletin, 108, 38-41.

Clark, N., Pain, D. \& Green, R. (2014) Saving the spoon-billed sandpiper: an update on the conservation programme. British Birds, $107,467-475$.

Flint, V.E. \& Kondratiev, A.Ya. (1977) An experience of evaluating the total number of a rare stenotypic species (spoon-billed sandpiper Eurynorhynchus pygmeus as an example). In 7 th All-Union Ornithology Conference: Abstracts of Talks (ed. M.A. Voinstvenski), p. 25o. Naukova Dumka, Kiev, USSR. [In Russian]

Gunnarsson, T.G., Gill, J.A., Pотts, P.M., Atkinson, P.W., Croger, R.E., Gélinaud, G. et al. (2005) Estimating population size in black-tailed godwits Limosa limosa islandica by colour-marking. Bird Study, 52, 153-158.

Gustafion, M.E., Hildenbrand, J. \& Metras, L. (1997) The North American Bird Banding Manual (Electronic Version). Version 1.o. Https://www.pwrc.usgs.gov/BBl/manual/ [accessed 1 July 2016].

IUCN (2001) IUCN Red List 2001 Categories \& Criteria (version 3.1). IUCN Species Survival Commission, Gland, Switzerland.

Jolly, G.M. (1965) Explicit estimates from capture-recapture data with both death and immigration-stochastic model. Biometrika, 52, 225-247.

Kirby, J. (2010) Review 2: Review of Current Knowledge of Bird Flyways, Principal Knowledge Gaps and Conservation Priorities. CMS Scientific Council: Flyway Working Group Reviews.

Le Cren, E.D. (1965) A note on the history of mark-recapture population estimates. Journal of Animal Ecology, 34, 453-454.
Manly, B.F.J. (2006) Randomization, Bootstrap and Monte Carlo Methods in Biology. Chapman \& Hall, London, UK.

Pain, D., Green, R. \& Clark, N. (2011) On the edge: can the spoon-billed sandpiper be saved? British Birds, 104, 350-363.

Piersma, T., Lok, T., Chen, Y., Hassell, C.J., Yang, H.-Y., Boyle, A. et al. (2015) Simultaneous declines in summer survival of three shorebird species signals a flyway at risk. Journal of Applied Ecology, 53, 479-490.

Ramsar Convention Bureau (1988) Proceedings of the Third Meeting of the Conference of the Contracting Parties (Regina, Canada, 27 May5 June 1988). Ramsar Convention Bureau, Gland, Switzerland.

SEBER, G.A.F. (1973) The Estimation of Animal Abundance and Related Parameters. Charles Griffin, London, UK.

Томкоvich, P.S. (1994) Spatial structure of the Spoon-billed Sandpiper (Eurynorhynchus pygmeus) population at breeding grounds. In Modern Ornithology 1992 (ed. E.N. Kurochkin), pp. 130148. Nauka Publishers, Moscow, Russia. [In Russian]

Tong, M., Clark, N., Zhang, L., Jing, L. \& Zöckler, C. (2014) The autumn Rudong SBS Survey 2013. Spoon-billed Sandpiper Task Force News Bulletin, 11, 9-10.

Tong, M., Zhang, L., Li, J., Zöckler, C. \& Clark, N.A. (2012) The critical importance of the Rudong mudflats, Jiangsu Province, China in the annual cycle of the spoon-billed sandpiper Calidris pygmeus. Wader Study Group Bulletin, 119, 208-211.

Weiser, E.L., Lanctot, R.B., Brown, S.C., Alves, J.A., Battley, P.F., Bentzen, R. et al. (2016) Effects of geolocators on hatching success, return rates, breeding movements, and change in body mass in 16 species of Arctic-breeding shorebirds. Movement Ecology, 4, 12.

W HITE, G.C. (1996) NOREMARK: population estimation from markresighting surveys. Wildlife Society Bulletin, 24, 50-52.

Zöckler, C., Syroechrovskiy, E.E. \& A trinson, P.W. (2010a) Rapid and continued decline in the spoon-billed sandpiper Eurynorhynchus pygmeus indicates imminent extinction unless conservation action is taken. Bird Conservation International, 20, 95-111.

Zöckler, C., Htin Hla, T., Clark, N., Syroechkovskiy, E., Yakushev, N., Daengphayon, S. \& Robinson, R. (2010b) Hunting in Myanmar is probably the main cause of the decline of the spoon-billed sandpiper Calidris pygmeus. Wader Study Group Bulletin, 117, 1-8.

Zöckler, C., Beresford, A.E., Bunting, G., Chowdhury, S.U., Clark, N.A., FU, VW.K.. et al. (2016) The winter distribution of the spoon-billed sandpiper Calidris pygmaeus. Bird Conservation International, http://dx.doi.org/10.1017/So959270915000295.

\section{Biographical sketches}

NigEL CLARK researches the demography of shorebirds and works to conserve them. He is the Scientific Advisor to the Spoon-billed Sandpiper Task Force. Gu y Anderson and Rhy s Gre en conduct research on conservation actions to recover threatened and declining bird populations. JING Li works to conserve the spoon-billed sandpiper and other shorebirds that depend on stop-over sites in the south-western Yellow Sea. Evgeny Syroechiovskiy chairs the Spoon-billed Sandpiper Task Force and leads conservation work on the species in Russia. Pavel Tomkovich is a shorebird biologist. He researched the breeding population of spoon-billed sandpipers 30 years ago and also in the last decade. CHRISTOPH ZÖCKLER is the Spoon-billed Sandpiper Task Force Coordinator and has undertaken many expeditions to locate the breeding and non-breeding areas of the species. Reвеcca LeE provided logistical support to the spoonbilled sandpiper expeditions to the Russian Arctic. She also works to improve the care and breeding success of captive populations of threatened waterbirds. 